\title{
GRAFFITI OCH ANNAN KRIMINALITET
}

\author{
- KRIMINELLA KARRIÄRER BLAND STOCKHOLMS GRAFFITIMÅLARE*
}

\section{AV DOKTORANDSTUDERENDE DAVID SHANNON}

This article presents findings from a study of the short term criminal career trajectories of 70 Stockholm graffitists. The results from a cluster analysis indicate the presence of a variety of career trajectories, including groups with little or no involvement in other forms of crime, and groups presenting considerably more extensive levels non-graffitirelated offending. Given this distribution, it seems unlikely that short term involvement with graffiti would entail a significantly increased risk for long term antisocial behaviour, independantly of pre-existing risk and protective factors. Long term involvement with the subculture may nonetheless involve exposure to influences likely to have an adverse effect on an individual's chances of returning to more conventional roles in adulthood.**

Graffitikulturen växte fram i de amerikanska städerna Philadelphia och New York under 1960- och 70-talen. Subkulturen kan sägas vara centrerad kring målandet av tags (kodifierade namnteckningar), throw ups (bokstavsbilder skrivna oftast med endast konturlinje) och pieces (mer fulländade bokstavsbilder, dvs 'graffitimålningar', vanligtvis målade med flera färger), som skrivs/målas främst på synliga allmänna ytor, och oftast utan tillstånd, dvs illegalt. ${ }^{1}$ Kring dessa olika former av graffiti har det utvecklats ett komplext normsystem som bl a reglerar fördelningen av status, 'fame', eller respekt bland de ungdomar som skriver och målar graffiti. Graffitin exporterades från USA som en del av hip-hopkulturen och fick sitt genombrott i de skandinaviska länderna under första hälften av 1980-talet. Sedan dess har saneringen av klotter/graffiti kostat allt större summor. Samtidigt har de organisationer som är mest drabbade (främst transportföretag och kommuner) växt fram som en enhetlig intressegrupp i sina försök att komma till rätta med problemet.

I Sverige har frågan om förhållandet mellan graffitikulturen och annan brottslighet aktualiserats i samband med uttalanden från poliser och andra aktörer inom anti-graffitirörelsen, vilka presenterat graffitilivsstilen som en inkörsport till grövre former av kriminalitet (jfr Johnson 2001:266). Syftet med förelig-

\footnotetext{
* Artikeln bygger delvis på forskningsrapporten "Graffiti and Adolescent Delinquency. An Analysis of Short Term Career Trajectories" (Shannon 2001). Forskningen har finansierats av Storstockholms Lokaltrafik AB (SL); Statens Järnvägar (SJ); Skolfastigheter i Stockholm AB (SISAB); Skandia/Idéer för Livet, samt Gatu- och fastighetskontoret, Stockholms stad.

** Title in English: Graffiti and Other Forms of Delinquency. Criminal Careers among Graffitists in Stockholm. Original in Swedish.
} 
gande studie är att belysa denna fråga utifrån en analys av kriminella karriärmönster bland Stockholms klottrare/graffitimålare. Undersökningen bygger främst på en klusteranalys där urvalet delas in i relativt homogena grupper med hänsyn till ett antal variabler, vilka i sin tur avser att mäta fem olika dimensioner av den kriminella karriären.

\section{Tidigare forskning}

Fjorton år har nu gått sedan Skyum-Nielsens (1987) banbrytande arbete om graffitimålare i Danmark. Perioden har bevittnat ett antal studier om graffitikulturen i Norden, vilka har bidragit med viktiga insikter om de beteendemönster och värderingar som karakteriserar denna subkultur. I likhet med den övriga internationella litteraturen har en del av dessa studier även behandlat frågan om förhållandet mellan graffiti och annan kriminalitet.

I såväl USA (Castleman [1982] 1997) som i Skandinavien (Thorsted 1997) har man funnit grupper bland graffitimålarna som också ägnar sig åt andra former av skadegörelse men som även uppvisar tecken på betydande våldsbenägenhet. I en studie genomförd av Transit Police i New York blev $40 \%$ av de arresterade 15-åriga graffitimålarna misstänkta för inbrott eller rån inom en treårig uppföljningsperiod (jfr Glazer 1979). Glazer drar slutsatsen att involvering i graffitikulturen för många verkar vara en del i en mer långvarig kriminell karriär.

Forskningsresultat av denna typ hör emellertid till undantagen. I majoriteten av de studier som genomförts såväl inom som utanför Norden framgår att klottrare/graffitimålare i regel inte är involverade i andra former av kriminalitet. Även om de flesta forskare är överens om att stölder av sprejburkar är en vanlig företeelse inom subkulturen, menar de att grövre brott är tämligen sällsynta bland graffitimålare ( $\mathrm{t}$ ex Feiner \& Klein 1982; Skyum-Nielsen 1987; Lachman 1988; Gusterman 1989; Lasley 1995; Ferrell 1996; Jacobson 1996; Maxwell 1997; Skardhammar 1998, 1999; Johnson 2001).

I rak motsats till polisens bild av en miljö som alstrar annan kriminalitet, har viss nordisk forskning dessutom hävdat att involvering i graffitikulturen egentligen har en positiv effekt på utvecklingen för många graffitimålare (Gusterman 1989; Jacobson 1996). Dessa författare menar att graffitilivsstilen kan uppfattas som en 'ovanlig läroprocess' (jfr Ziehe 1986) där ungdomar får en möjlighet att utvecklas både socialt och kreativt, på ett sätt som gör dem bättre rustade att möta vuxenlivets många utmaningar.

Forskningen har ändå visat att graffitins status som brottslig handling utgör en viktig spänningskälla. Denna spänning anses vara ett centralt element i graffitins attraktionskraft för många, i synnerhet de yngre graffitimålarna (SkyumNielsen 1987:23; Skardhammar 1999:91; Ferrell 1996:148; Maxwell 1997:57, 60). Andra aktiviteter som har blivit förknippade med åtminstone vissa delar av graffitikulturen - som t ex att 'surfa' på tåg (att åka på utsidan eller taket av 
tunnelbane- och tågvagnar) eller att 'trasha' (dvs totalförstöra inredningen i) tunnelbanevagnar - stämmer inte heller speciellt väl in med tanken om en livsstil som skulle kunna ha en ensidigt positiv effekt på den personliga utvecklingen. Det verkar sannolikt att förhållandet mellan involvering i graffiti och ett varaktigt antisocialt beteende är mer komplext än vad som ibland har beskrivits inom delar av graffitiforskningen och anti-graffitirörelsen.

De studier som har behandlat denna frăga i Norden har nästan uteslutande utgått från en intervjubaserad metodologisk ansats, med mellan fyra (Skardhamar 1998) och 16 (Johnson 2001) intervjupersoner. Det enda undantaget är Jacobsons (1996) enkätundersökning med 45 målare på en graffitiskola i Uppsala. Föreliggande studie belyser förhållandet mellan involvering i graffitikulturen och andra former av kriminalitet utifrån ett urval av 70 kända klottrare/graffitimålare i Stockholms län. Genom användning av en longitudinell ansats och registerdata fyller studien ett tomrum i den befintliga forskningen på området.

\section{Karriäransatsen}

Med begreppet kriminell karriär menas "the longitudinal sequence of offences committed by an individual offender" (Farrington 1992:8). I Sverige har Sarnecki $(1986: 103 ; 1987: 84 f)$ diskuterat ett antal element som ingår i en typisk karriärutveckling hos ungdomar med ett varaktigt antisocialt beteende. I en presentation som på många sätt motsvaras av den som utvecklats av Le Blanc och Frechette (1989) i den anglosaxiska litteraturen, beskriver Sarnecki en karriär som vanligtvis börjar med ett antal olika, mindre allvarliga förseelser. Med tid går dessa över i en mer allvarlig brottslighet för dem som fortsätter inom den antisociala karriärbanan. Narkotikamissbruk ingår i beteendemönstret för en del av dem som fortfarande är kriminellt aktiva under de senare tonåren, men vid denna tidpunkt har den stora majoriteten redan brutit sin kriminella karriär. Populationen av unga lagöverträdare innefattar således en större grupp vars lagöverträdelser är begränsad i tid till en kortare period under ungdomstiden samt en mindre grupp som fortsätter med ett antisocialt beteende in i vuxenåldern (jfr Moffit 1993). Samtidigt förekommer det typiskt en spridning av brotten över ett antal olika brottstyper under karriären och en viss ökning över tid i brottens grovhet för dem som förblir kriminellt aktiva.

Denna bild kan ställas mot litteraturens framställningar av den typiska graffitikarriären (Skyum Nielsen 1987; Jacobsson 1996; Johnson 2001). Här finns det t ex ofta en tydlig progression från 'taggare' till duktig målare eller 'bomba$\mathrm{re}^{{ }^{2}}$. Men denna utveckling sker inom en enda brottskategori. Med undantag för vissa graffitirelaterade brott ( $\mathrm{t}$ ex stölder av sprejburkar) har graffitimålare vanligtvis framställts som specialister. De ägnar sig mer eller mindre uteslutande åt en enda form av lagöverträdelse, utan några tecken på ökad grovhet i kriminaliteten över tid eller spridning till andra brottstyper. 


\section{Data}

Denna studie bygger på ett urval som i huvudsak inkluderar de ungdomar som år 1995 blev tagna på bar gärning i samband med klotter/graffitibrott på egendom tillhörande Storstockholms Lokaltrafik (SL) AB. I ett försök att få en större bredd på urvalet, togs även de med som samma år misstänktes för graffiti på Statens Järnvägars (SJ) och Stockholms stads egendom. I de fall polisens register över anmälda brott visade att dessa individer blivit misstänkta för ytterligare klotter/graffitibrott under 1995, inkluderades även deras medmisstänkta vid dessa tillfällen i urvalet. Respektive graffitimålares kriminella karriär har följts i polisens RAR $^{3}$-register från juli år 1994, när RAR data för hela Stockholms län blev tillgängliga för första gången, till och med mars år 1999.

Den del av urvalet som avhandlas i denna artikel innefattar 70 ungdomar som alla var i åldern 13-14 år vid början av observationsperioden. Av dessa var endast en flicka. Numerärt är pojkar mycket starkt överrepresenterade inom graffitikulturen (jfr Skyum-Nielsen 1987; Carrington 1989; Brewer \& Miller 1990; Jacobson 1996), men utifrån tidigare forskning förefaller det sannolikt att könsfördelningen i det aktuella urvalet ändå underskattar flickornas representation bland klottrare/graffitimålare i Stockholm (t ex Axnäs 2000:18).

Även bortsett från könsfördelningen kan representativiteten i ett urval av denna typ alltid ifrågasättas. Exempelvis är 'nybörjare' förmodligen underrepresenterade då intervjudata tyder på att det bland dessa är vanligt att börja tagga främst i nära anslutning till hemmet och skolan. Tunnelbane- och pendeltåg blir attraktiva som måltavlor först senare, när ungdomarna hunnit lära sig mer om graffitins traditioner, i synnerhet den speciella status som tåggraffitin erhåller inom kulturens värdesystem. Men i och med att graffitimålare utgör en synnerligen dold population, saknas det helt enkelt en optimal lösning till urvalsproblematiken (jfr Tiby 1999:40ff). Som komplement till polisens registerdata ingick dessutom ett antal intervjuer med aktiva eller före detta graffitimålare i undersökningen. Intervjudata har använts som stöd vid tolkning av resultaten från registerstudien. ${ }^{4}$

\section{Variabler}

Ungdomarnas kriminella karriärer har specificerats med hjälp av tretton variabler som fångar följande fem dimensioner av den kriminella karriären.

\section{Graffitikarriären}

Här mäts omfattningen av ungdomarnas involvering i graffiti och graffitirelaterade lagöverträdelser. Graffitikarriärdimensionen omfattar brottstyperna klotter/graffiti samt stölder av sprejfärg eller graffititidningar.

\section{Lindrigare brott}

Mäter ungdomarnas involvering i mindre allvarliga former av lagöverträdelse 
som är relativt vanliga bland ungdomar; snatteri, alkoholkonsumtion (som minderårig), tjuvåkning samt andra former av skadegörelse.

\section{Grövre brott}

Denna dimension fångar upp ungdomarnas involvering i grövre, mindre vanliga brottstyper; bilstöld, annan stöld (ej snatteri), häleri, bedrägeri, hot, våld (inklusive sexbrott), inbrott, rån och narkotikabrott.

\section{Den totala brottskarriären}

Ett mått på ungdomarnas involvering i alla former av lagstridiga beteenden. Här ingår graffitirelaterade brott, lindrigare och grövre brott, samt även ett par andra brottstyper ( $\mathrm{t}$ ex våld mot tjänsteman) som inte togs med $\mathrm{i}$ antingen den lindrigare eller den grövre brottsvariabeln. ${ }^{5}$

\section{Specialisering kontra spridning}

Denna variabel mäter graden av specialiseringen hos den kriminella karriären. Måttet bygger på tanken om en ökning över tid i brottens grovhet, och går ut på en sexdelad kategorisering av brottstyper: snatteri/skadegörelse; inbrott/häleri; bilstöld/annan stöld; rån; narkotikabrott.

Observationsperioden delades in i tio sexmånadersperioder. Karriären i förhållande till de fyra brottskategorierna (graffiti, lindriga, grövre, och den totala karriären) mäts sedan med två variabler som fångar upp karriärlängden, samt en som specificerar när det senaste brottet inträffade. Det första längdmåttet räknar med antalet sexmånadersperioder mellan de första och sista brotten av respektive typ. Det andra räknar med antalet sexmånadersperioder när individen registrerats som misstänkt i samband med respektive brottskategori. Dessa båda mått har tidigare använts i nordisk karriärforskning. Kyvsgaard (1998) har till exempel använt den första, medan Wikström (1987) däremot nämner båda men väljer att enbart använda den andra. Anledning till att båda har använts i denna studie är att de täcker in delvis olika aspekter av karriärlängdsbegreppet. Den första, som endast beräknar tidsavstånd mellan de första och senaste brotten, ignorerar skillnader i kontinuiteten hos den kriminella karriären. Dessa fångas emellertid upp av den andra variabeln. Variabeln som mäter specialisering kontra spridning bildades som ett enkelt additivt index över antalet olika brottstyper (av sex möjliga) som ingick i respektive individs kriminella karriär. Samtliga variabler, med minimi- och maximivärden, medelvärden och standardavvikelser redovisas i tabell 1 . 
Tabell 1. Min. \& max. värden, medelvärde and standardavvikelse för variablerna i analysen (enheter: sexmånadersperioder; brottstyper)

\begin{tabular}{llrll}
\hline Variable & Min. & Max. & $\begin{array}{l}\text { Medel } \\
\text {-värde }\end{array}$ & Std. Av. \\
& & & & \\
Graffiti & 1.0 & 10.0 & 2.5 & 2.2 \\
Längd a & 1.0 & 9.0 & 2.0 & 1.6 \\
Längd b & 2.0 & 10.0 & 3.7 & 2.1 \\
Längd c & & & & \\
Grövre brott & 0 & 10.0 & 2.6 & 3.2 \\
Längd a & 0 & 7.0 & 1.5 & 1.8 \\
Längd b & 0 & 10.0 & 4.3 & 3.9 \\
Längd c & & & & \\
Lindrigare brott & 0 & 9.0 & 1.4 & 2.3 \\
Längd a & 0 & 7.0 & 0.9 & 1.3 \\
Längd b & 0 & 10.0 & 2.4 & 3.0 \\
Längd c & & & & \\
Total brottskarriär & & 10.0 & 5.2 & 3.0 \\
Längd a & 1.0 & 10.0 & 3.4 & 2.1 \\
Längd b & 1.0 & 10.0 & 6.2 & 2.6 \\
Längd c & 2.0 & & & \\
Spridning & 0 & 6.0 & 1.7 & 1.6 \\
\hline
\end{tabular}

a: mätt från perioden för första till senaste brottet

b: mätt som antalet sex-månadersperioder när ett brott begås

c: mätt från observationsperiodens början till perioden för senaste brottet

I och med att samtliga variabler mäter olika aspekter av ett grovt karriärbegrepp, skulle det vara överraskande om det inte fanns en viss grad av samvariation dem emellan. Detta orsakar dock problem i samband med klusteranalys eftersom den dimension som mäts av de korrelerade variablerna tilldelas oproportionerligt stor vikt i beräkningarna (jfr Aldenderfer \& Blashfield 1987:257; Jones \& Harris 1999:257). För att undvika dessa problem genomfördes en principalkomponentanalys för att få fram ett fåtal okorrelerade, sammansatta variabler som ändå skulle fånga upp variansen i de ursprungliga måtten. Tre komponenter behölls ( $i$ enlighet med regeln om 'eigenvärden' större än ett), och dessa roterades med varimaxmetoden för att få fram mer tolkbara komponenter samtidigt som nollkorrelationen mellan komponenterna bevarades. Den roterade komponentmatrisen redovisas i tabell 2. 
Tabell 2. Roterad komponentmatris. Principalkomponentanalys med varimax rotation $(N=70$; kumulativ andel av förklarad varians $=87 \%)$

\begin{tabular}{llll}
\hline Variabel & $\begin{array}{l}\text { Komponent 1 } \\
\text { (Graffiti-relaterad } \\
\text { brottslighet) }\end{array}$ & $\begin{array}{l}\text { Komponent 2 } \\
\text { (Lindrigare } \\
\text { brottslighet) }\end{array}$ & $\begin{array}{l}\text { Komponent 3 } \\
\text { (Grövre } \\
\text { brottslighet) }\end{array}$ \\
\hline Graffiti & & & \\
Längd a & $\mathbf{0 , 9 4}$ & 0,21 & 0,16 \\
Längd b & $\mathbf{0 , 8 5}$ & 0,30 & 0,23 \\
Längd c & $\mathbf{0 , 9 5}$ & 0,20 & 0,02 \\
Lindrigare brott & & & \\
Längd a & 0,28 & $\mathbf{0 , 8 5}$ & 0,27 \\
Längd b & 0,23 & $\mathbf{0 , 8 4}$ & 0,34 \\
Längd c & 0,30 & $\mathbf{0 , 7 7}$ & 0,26 \\
Grövre brott & & & $\mathbf{0 , 8 5}$ \\
Längd a & $-0,02$ & 0,36 & $\mathbf{0 , 7 8}$ \\
Längd b & 0,05 & 0,46 & $\mathbf{0 , 9 3}$ \\
Längd c & $-0,01$ & 0,17 & \\
& & & $\mathbf{0 , 8 7}$ \\
Total brottskarriär & & 0,17 & $\mathbf{0 , 6 8}$ \\
Längd a & 0,34 & 0,47 & $\mathbf{0 , 8 2}$ \\
Längd b & 0,47 & 0,08 & $\mathbf{0 , 7 8}$ \\
Längd c & 0,40 & 0,48 & \\
Spridning & 0,14 & & \\
\hline
\end{tabular}

a: mätt från perioden för första till senaste brottet

b: mätt som antalet sex-månadersperioder när ett brott begås

c: mätt från observationsperiodens början till perioden för senaste brottet

Siffrorna i fetstil i tabell 2 representerar respektive variabels största komponentladdning. Komponenterna har rubricerats utifrån de variabler med högst laddning. Urvalets värden på de ursprungliga 13 variablerna översattes sedan till tre komponentvärden.

\section{Klusteranalysen}

Klusteranalysen är en multivariatmetod som avser att ordna ett urval i homogena grupper. Grundtanken är att de kluster (dvs grupper) som framträder ska innehålla fall som liknar varandra i förhållande till vissa relevanta egenskaper. Samtidigt ska fall fördelade i olika kluster vara så olika som möjligt. I föreliggande studie är det ungdomarnas kriminella karriärer som är av intresse. Klusteranalsyen används här främst för att låta datamaterialet självt berätta om eventuella skillnader bland graffitimålarnas kriminella karriärer (jfr Brennan 1987:204). 
De 70 ungdomarna i urvalet indelades i kluster utifrån deras komponentvärden på tre karriärdimensioner - grövre brott, graffitirelaterade brott respektive lindrigare brott. Klusteranalysen genomfördes i två steg (jfr Punj \& Stewart 1983:143; Milligan 1999:361). Först bildades konsensuslösningar med hjälp av tre hierarkiska klustringsmetoder: 'average-linkage', 'complete-linkage' och 'Ward's method' med kvadrerat euklidiskt avstånd som avståndsmått. Lösningarna på tre olika nivåer (3-kluster, 4-kluster och 5-kluster) granskades sedan närmare efter att dessa först hade finjusterats med en $\mathrm{s} \mathrm{k}$ ' $k$-means' indelning, vilken är mindre känslig än de hierarkiska metoderna för inverkan av extrema värden (jfr Milligan 1999:347). Den lösning med fyra kluster visade sig bäst illustrera karaktären av de karriärvariationer som trädde fram i intervjumaterialet.

\section{Resultat}

Genomsnittsprofiler för de slutgiltiga klustren redovisas i figurerna 1-2 nedan. Profilerna bygger på två av tre karriärlängdsvariabler, nämligen karriärlängden mellan de första och senaste brotten, samt tidpunkten för det senaste brottet på respektive dimension, vilken används i egenskap av fixeringspunkt. Dessutom redovisas spridningsvariabeln. ${ }^{6}$

Storleken på de fyra klustren varierar avsevärt. Drygt 70 procent av individerna (51 av 70) ryms inom två stora kluster.

Figur 1. Medelvärdesprofiler för de slutgiltiga'k-means' kluster 1 och 2.
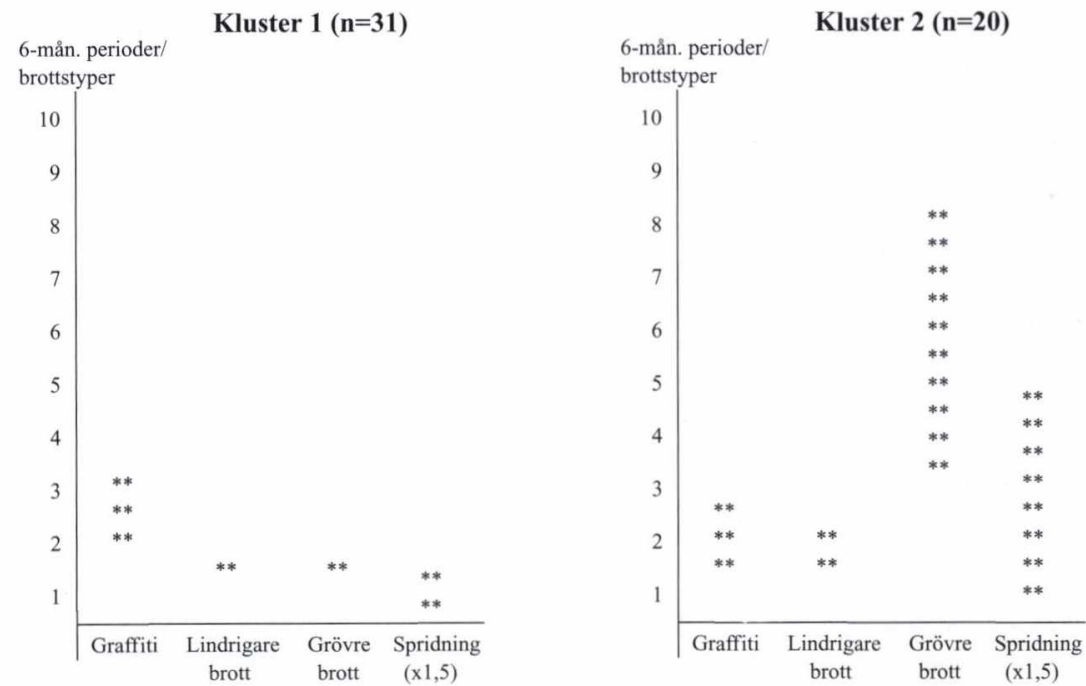
Det största klustret (Kluster 1 - figur 1) innehåller 31 individer som kan karakteriseras som tillfälliga lagöverträdare. Efter att ha åkt fast för klotter/graffiti en gång, eller högst två till tre gånger, försvinner dessa personer från polisens register mer eller mindre totalt. En del av dem har begått ett och annat brott vid sidan om sina graffitirelaterade lagöverträdelser, men det låga värdet på spridningsvariabeln tyder på att denna typ av beteenden hör till undantaget snarare än regeln. Enligt polisregistret består denna grupp av ungdomar som i allt väsentligt kan betraktas som icke-kriminella utifrån ett långsiktigt perspektiv.

Det andra stora klustret (Kluster 2 - figur 1) består av 20 fall. Klustrets karriärmönster innefattar en kort tid med graffitirelaterade brott $\mathrm{i}$ början av observationsperioden. Annars utgör profilen ett tämligen klassiskt exempel av den kriminella karriär som diskuterats som typisk för dem med ett varaktigt antisocialt beteende under ungdomstiden. Karriären inleds med ett antal mindre allvarliga förseelser, $\mathrm{t}$ ex snatteri, tjuvåkning och skadegörelse. Med tiden går dock dessa ungdomar över till en grövre brottslighet med bl a bilstölder, inbrott, hot och våld samt ibland även narkotikabrott. Denna grupp karakteriseras av relativt höga värden på spridningsvariabeln.

Figur 2. Medelvärdesprofiler för de slutgiltiga'k-means 'kluster 3 och 4.
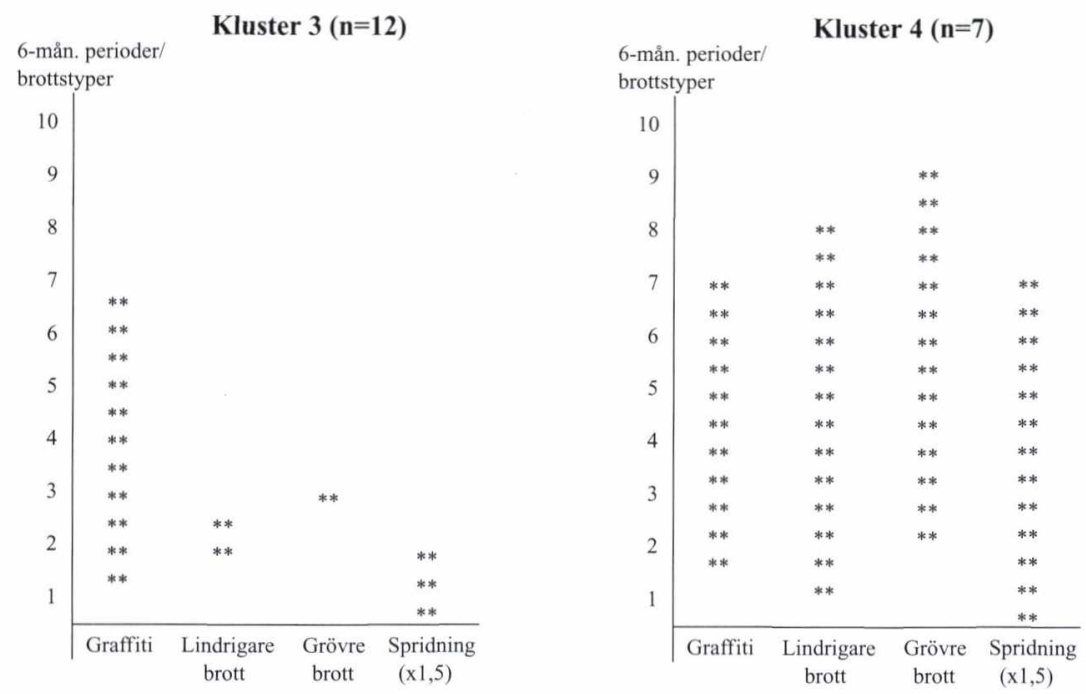
De andra två klustren innehåller ungdomar som är aktiva inom graffitikulturen under lång tid. Den ena gruppen (Kluster 3 - figur 2) består av 12 ungdomar vars karriärmönster på många sätt påminner om den som presenterats i större delen av den tidigare graffitikarriärforskningen. Dessa ungdomar håller sig mer eller mindre exklusivt till graffitirelaterade brott, trots en lång karriär, och kan karakteriseras som graffitispecialister. Den sista gruppen (Kluster 4 - figur 2) är mycket annorlunda. Detta kluster består av ett litet antal (7) ungdomar med en omfattande belastning med avseende på samtliga karriärdimensioner samt ett mycket högt värde på spridningsvariabeln.

Samma bild erhålls vid en jämförelse av det genomsnittliga antalet brott som begås av ungdomarna i de fyra klustren. Figur 3 illustrerar dessa skillnader för ett antal utvalda brottskategorier.

Figur 3. Medelvärdesklusterprofiler för antalet brott begågna i sex utvalda brottskategorier.

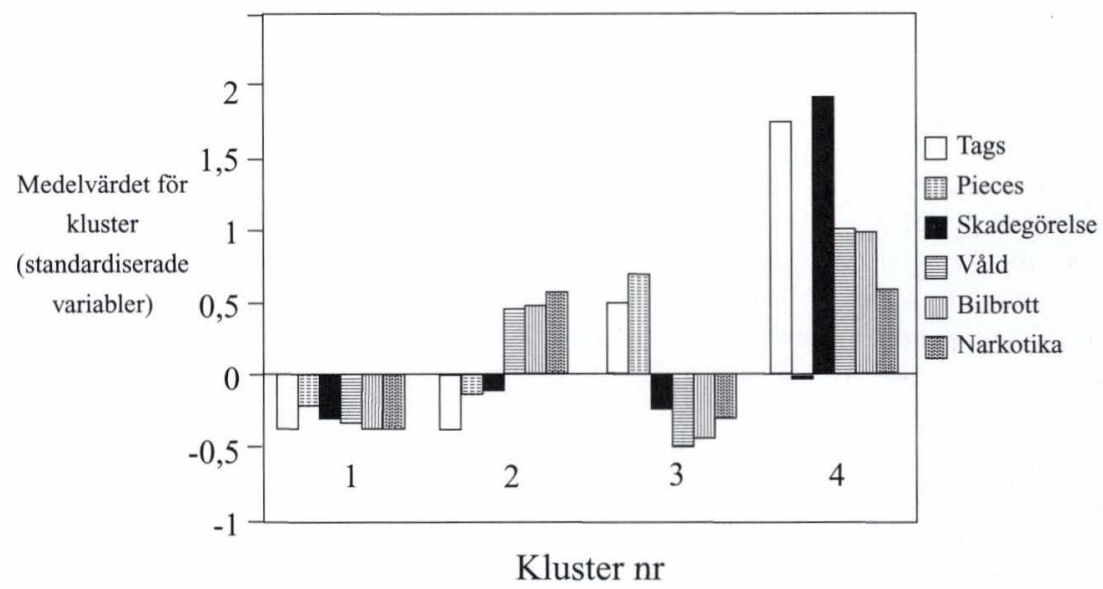

Variablerna i figur 3 har standardiserats för att kunna få mindre vanliga brottstyper ( $\mathrm{t}$ ex narkotikabrott) och mer vanliga sådana ( $\mathrm{t}$ ex 'tags' och 'pieces') i samma diagram. Nollinjen representerar genomsnittsantalet brott per person inom de olika brottskategorierna för urvalet som helhet.

Som väntat ligger antalet brott begångna av de tillfälliga lagöverträdarna (Kluster 1) under genomsnittet i samtliga brottskategorier. Ungdomarna i Kluster 2 (vars karriärmönster beskrivits som typiskt för ungdomar med ett mer varaktigt antisocialt beteende) ligger under genomsnittet vad gäller tags, pieces och skadegörelse. Däremot begår de fler vålds-, bil- och narkotikabrott. Graffi- 
tispecialisterna (Kluster 3) kännetecknas av relativt omfattande tags- och piecesproduktion. Det går alltså inte att dela in graffitikulturen i dem som taggar och dem som skapar de större målningarna (pieces). 'Målarna' skriver också en hel del tags (jfr Skyum Nielsen 1987:5). Dessa ungdomar ligger däremot under genomsnittet i samtliga andra brottskategorier. I Kluster 4 är brottsbelastningen genomgående mycket hög med undantag för uppförandet av pieces. Trots att denna grupp innehåller endast tio procent av urvalet (sju individer), svarar dessa för 53 procent av samtliga lindrigare brott i materialet (inklusive hela 60 procent av skadegörelsefallen) samt 28 procent av de grövre brotten.

Två av de sju individerna i Kluster 4 har blivit misstänkta för att ha målat pieces. För detta kluster som helhet ligger dock målandet av pieces lite under genomsnittet för urvalet som helhet. Uppförandet av graffitimålningar är således starkt koncentrerade till graffitispecialisterna i Kluster 3. Ungdomarna i Kluster 4 verkar däremot vara betydligt mer fokuserade på tags samt de mer skadegörelserelaterade inslagen i graffitikulturen. Samtidigt begår de även andra grova brott i relativt stor utsträckning.

\section{Diskussion}

De ungdomar som i någon mån blir involverade i graffitikulturen utgör alltså en ganska heterogen grupp. Bland dem vars involvering i graffitikulturen sträcker sig över en längre tid finns det individer som inte är brottsbenägna $\mathrm{i}$ övrigt och som inte heller dras med $i$ andra former av kriminalitet trots en lång karriär av graffitirelaterade lagöverträdelser. Samtidigt finns det en grupp med relativt tung brottsbelastning. Det finns även stöd för de resultat som Transit Police i New York kommit fram till, dvs att involveringen i graffitikulturen för många utgör en övergående fas i en vanlig, mer bestående kriminell karriär.

På många sätt bekräftar dessa resultat de olika delbilder som tidigare har presenterats i forskningen på området. Nytt är emellertid att denna studie för första gången presenterar en helhetsbild, där samtliga delar på ett överskådligt sätt ställs i förhållande till varandra. Detta skapar i sin tur en bättre grund för att försöka förstå t ex graffitikulturens attraktionskraft och konsekvenser för ungdomar med olika förutsättningar och mål.

I fråga om graffitimålarnas övriga brottslighet uppvisar denna subkultur en snedfördelning som i allt väsentligt liknar den som generellt kännetecknar ungdomars kriminalitet (jfr Rutter m fl 1998; Ring 1999, 2000; von Hofer 2001). A ena sidan återfinns en relativt stor grupp med låg brottsbelastning, å andra sidan en mycket liten grupp som svarar för en betydande andel av kriminaliteten. I samband med försök att förklara denna snedfördelning har ett brett spektrum av möjliga risk och skyddsfaktorer åberopats inom den kriminologiska litteraturen.

Frågan är om det mot bakgrund av dessa resultat är rimligt att betrakta graffitilivsstilen i sig som en avgörande riskfaktor eller inkörsport till fortsatt och tilltagande brottslighet. Två av de profiler som framträdde i klusteranalysen kan 
möjligen tolkas som stöd för en sådan hypotes: Kluster 2 - där klotter och graffiti finns med bland andra former av lindriga brott vid inledningen av en typisk antisocial karriärutveckling - samt Kluster 4, där individerna har en lång karriär av taggande i kombination med såväl lindriga som grova brott. Kluster 1 och 3, med sin begränsade inblandning $i$ annan kriminalitet, utgör däremot en tydlig motvikt till detta stöd. Karriärmönstret för de mer tillfälliga lagöverträdarna tyder på att involveringen i graffitikulturen för många är en kortvarig erfarenhet som överhuvudtaget inte leder vidare till ett fortsatt antisocialt beteende. Därmed förefaller det osannolikt att graffitikulturen i sig skulle utöva någon avgörande brottsalstrande påverkan oberoende av bakomliggande risk och skyddsfaktorer.

Därmed inte sagt att en längre vistelse i graffitins subkulturella miljö behöver utgöra ett utpräglat positivt inslag i dessa ungdomars utveckling, vilket ibland har hävdats. De intervjuer med graffitimålare som har genomförts i samband med studien visar att graffitin för vissa kan bli till en så central del i vardagen att de mer eller mindre slutar fungera i andra viktiga sammanhang, t ex i skolan. Dessutom finns en ständig risk för att gripas av polisen eller på andra sätt bemötas av en negativ reaktion från representanter för vuxenvärlden. Dessa reaktioner kan också öka sannolikheten för att längre fram drabbas av en negativ utveckling (jfr Laub \& Sampson 1993:306). Vidare bekräftar intervjumaterialet att involvering i graffitikulturen innebär en utsatthet för kriminella influenser (jfr Ring 1999:18ff). Bland annat finns ett normativt stöd för andra former av skadegörelse (t ex 'trashing'), samt spännings- och risksökande beteenden (exempelvis 'surfing' på tåg). Dessa normer är dock inte allenarådande inom graffitikulturen, och det är långt ifrån alla klottrare/graffitimålare som är lockade av eller deltar i sådana aktiviteter. För de som internaliserar dessa normer kan det emellertid finnas risk för en utveckling av habitualiserade beteendemönster och en självuppfattning där det sedan kan bli svårt att finna konventionella roller i samhället givande eller tillfredsställande (jfr Matsueda \& Heimer 1997).

\section{LITTERATUR:}

Aldenderfer, M. \& Blashfield, R. (1987): Cluster Analysis, Sage, Beverly Hills

Axnäs, N. (2000): Graffiti, brottslighet och narkotikabruk bland elever i årskurs 9, D-uppsats i kriminologi, Kriminologiska institutionen, Stockholms universitet

Brennan, T. (1987): "Classification: An Overview of Selected Methodological Issues." Gottfredson, D.M. \& Tonry, M. (Eds.) Crime and Justice, A Review of Research 9, s 201-248

Brewer, D. \& Miller, L. (1990): "Bombing and Burning: The Social Organisation and Values of Hip Hop Graffiti Writers and Implications for Policy." Deviant Behaviour 11, s 345 -369

Carrington, K. (1989): "Girls and Graffiti." Cultural Studies 3, s 89-100

Castleman, C. (1997): Getting Up, Subway Graffiti in New York, The MIT Press, Cambridge, Massachusetts

Farrington, D. P. (1992): “Criminal Career Research: Lessons for Crime Prevention.” Studies on Crime and Crime Prevention 1, s 7-29 
Feiner, J. \& Klein, S. (1982): “Graffiti Talks.” Social Policy Winter 1982, s 47-53

Ferrell, J. (1996): Crimes of Style, Northeastern University Press, Boston

Glazer, N. (1979): "On subway graffiti in New York.” The Public Interest 54, s 3-11

Gusterman, L (1989): Hiphop - jag lever. Om tio graffitimålande ungdomar i Stockholm. C-uppsats i etnologi, Etnologiska institutionen, Stockholms universitet

von Hofer, H. (2001): “Åtgärder mot ungdomsbrottslighet.” In Estrada, F. \& Flyghed, J. (Red.) Den Svenska Ungdomsbrottsligheten, s 317-331, Studentlitteratur, Lund

Jacobson, S. (1996): Den spraymålade bilden: Graffiti som bildform, konströrelse och läroprocess, Aerosol Art Archives, Lund

Johnson, M. (2001): “Graffiti - utifrån målarnas synvinkel.” I Estrada, F. \& Flyghed, J. (Red.) Den svenska ungdomsbrottsligheten, s 260-292, Studentlitteratur, Lund

Jones, P. R. \& Harris, P.W. (1999): "Developing an Empirically Based Typology of Delinquent Youths." Journal of Quantitative Criminology 15, s 251-276

Kyvsgaard, B. (1998): Den kriminelle karriere, Jurist- og Økonomförbundets Forlag, Copenhagen

Lachman, R (1988): "Graffiti as Career and Ideology." American Journal of Sociology 94, s 229-250

Lasley, J. (1995): "New Writing on the Wall: Exploring the Middle Class Graffiti Writing Subculture." Deviant Behaviour 16, s 151-167

Laub, J. H. \& Sampson, R. J. (1993): "Turning Points in the Life Course: Why Change Matters to the Study of Crime." Criminology 31, s 301-326

Le Blanc, M. \& Fréchette, M. (1989): Male Criminal Activity from Childhood Through Youth; Multilevel and Developmental Perspectives, Springer-Verlag, New York

Matsueda, R. L. \& Heimer, K. (1997): "A Symbolic Interactionist Theory of Role-Transitions, Role Commitments, and Delinquency." In Thornberry, P. (Red.) Developmental Theories of Crime and Delinquency, Advances in Criminological Theory, Vol. 7, s 163-214, Transaction Publishers, New Brunswick

Milligan, G. W. (1999): “Clustering Validation: Results and Implications for Applied Analyses." In Arabie, P., Hubert, L. J. \& De Soete, G. (Red.) Clustering and Classification, s 341-375, World Scientific, Singapore

Moffitt, T. E. (1993): "Adolescence-Limited and Life-Course-Persistent Antisocial Behaviour: A Developmental Taxonomy", Psychological Review 100, s 674-701

Ring, J. (1999): Hem och skola, kamrater och brott, Avhandlingsserie No. 2, Kriminologiska institutionen, Stockholms universitet

Ring, J. (2000): Stöld, våld och droger bland pojkar och flickor i årskurs nio, Brå-report 2000:17, Brottsförebygganderådet, Fritzes, Stockholm

Rutter, M., Giller, H. \& Hagell, A. (1998): Antisocial Behaviour by Young People, Cambridge University Press, New York

Sarnecki, J. (1986): Delinquent Networks, Brå-report 1986:1, Brottsförebygganderådet, Stockholm

Sarnecki, J. (1987): Skolan och brottsligheten, Carlsson Bokförlag, Stockholm

Shannon, D. (2001): Graffiti and Adolescent Delinquency - An Analysis of Short Term Career Trajectories, Report 2001:3, Kriminologiska institutionen, Stockholms universitet

Skardhamar, T. (1998): Graffiti - estetikk og kulturell motstand, Stensilserien nr 90, Institut for kriminologi, Oslo

Skardhamar, T. (1999): "Haerverkets estetikk." Materialisten 1, s 75-99

Skyum-Nielsen, A. (1987): "Graffiti - en kriminologisk undersøgelse." Justitia 10, s 1-29

Thorsted, S (1997): "Noget det bryder med det paene og rene." C-uppsats i sociologi, Sociologiska institutionen, Lunds universitet

Tiby, E. (1999): Hatbrott? Homosexuella kvinnors och mäns berättelser om utsatthet för brott, Avhandlingsserie $\mathrm{Nr}$ 1, Kriminologiska institutionen, Stockholms universitet

Wikström, P-O. (1987): Patterns of Crime in a Birth Cohort. Age, Sex, and Social Class Differences, Project Metropolitan Research Report No. 24, Department of Sociology, University of Stockholm Ziehe, T. (1986): Ny ungdom - om ovanliga läroprocesser, Norstedts, Malmö 
Noter:

I I Sverige har i synnerhet 'tags', men även till viss del de andra två graffitiformerna, också fått beteckningen 'klotter'.

2 En taggare som specialiserar sig på att skriva/måla så många tags som möjligt på ett begränsat område, exempelvis inuti en tunnelbanevagn.

3 Rationell anmälansrutin

4 För en mer utförlig beskrivning av de överväganden som styrde urvalet och val av datakälla hän visas till Shannon 2001, s 28-40.

5 Våld mot tjänsteman inkluderades inte bland våldsbrotten då dessa brott dök upp nästan uteslutande i samband med att en individ anhölls, emellanåt av polisen, men vanligtvis av de privatanställda väktare som jobbar på uppdrag av SL. Att likställa dessa med andra våldsbrott, t ex misshandel, skulle innebära att studiens datamaterial förvrängdes. Att registreras som miss tänkt i samband med dessa överträdelser innebär ändå att handlingen definieras som brottslig av polisen. Dessa brott togs följaktligen med i beräkningar av den totala brottskarriären.

6 Spridningsvariabeln har först multiplicerats med en faktor av 1,5 för att ge den en variationsvidd som är jämförbar med de andra variablerna i profilen.

Adress: Kriminologiska Institutionen

Stockholms universitet

SE - 10691 Stockholm

e-post: david.shannon@crim.su.se 